\title{
Sección Especial: El español en los Estados Unidos y el español en contacto con otras lenguas
}

\author{
ANTONIO MEDINA RIVERA* \\ ALBERTO PASTOR** \\ EDITORES INVITADOS
}

Recepción: 5 de enero de 2020

Aprobación: 20 de mayo de 2020

Forma de citar este artículo: Medina R, A. \& Pastor, A. (2020). El español en los Estados Unidos y el español en contacto con otras lenguas. Cuadernos de Lingüística Hispánica, (36), 131-134.

https://doi.org/ 10.19053/0121053X.n36.2020.11307

** Professor and chair in the Department of World, Languages, Literatures \&amp; Cultures at Cleveland State University. He received his PhD in Hispanic Linguistics at the University of Southern California. His areas of research include Spanish in the US with special focus on Spanish and the US Catholic Church, language maintenance, and Language attitudes. He is the editor of the Journal of Cultural Encounters, Conflicts \&amp; Resolutions. E-mail: a.medinarivera@csuohio.edu Đhttps://orcid.org/00000003-2361-6513.

*** Associate professor of Spanish and General Linguistics at Southern Methodist University (Dallas, TX). His research interests are twofold: Spanish syntax and Spanish sociolinguistics. His studies on Spanish syntax focus on the syntax-semantics interface, specifically degree constructions in the adjectival and nominal domains. Additionally, he explores issues related to Spanish in the United States such as language contact phenomena, languagemaintenance/loss, language ideologies and attitudes, and linguistic landscape. E- mail: apastor@smu.edu @https://orcid.org/0000-0001-7880-4170 


\section{Introducción}

La siguiente sección de este volumen de Cuadernos de Lingüística incluye cinco trabajos que se presentaron en el XXVII Congreso del Español en los Estados Unidos y XII Congreso del Español en Contacto con Otras Lenguas, los cuales se celebraron en Cleveland, Ohio del 4-6 de abril de 2019. La historia del Congreso de Español en los Estados Unidos se remonta al 1983 en la University of Illinois-Chicago, mientras que el primer congreso del Español en Contacto con Otras Lenguas se celebró en la University of Southern California en 1991. Ambos congresos atraen a especialistas en las áreas de lenguas en contacto, políticas del lenguaje, mantenimiento lingüístico y actitudes lingüísticas. ${ }^{1}$ Con esta sección incluida en el presente volumen de Cuadernos de Lingüística mantenemos la tradición de ofrecer al público algunos de los trabajos en dicha disciplina. Agrademos a la Dra. Lucía Bustamante por permitirnos colaborar con su revista y establecer un contacto que nos dirija a trabajar en futuras colaboraciones.

La sección cuenta con tres trabajos de investigación sobre el español en los Estados Unidos y dos trabajos enfocados en el español en contacto con otras lenguas. Los trabajos investigativos sobre el español para estudiantes de herencia en los Estados Unidos han tomado auge en los últimos años entre académicos de los Estados Unidos. Los niveles de dominio entre los estudiantes de herencia varían grandemente, al igual que los programas que ofrecen las diferentes universidades en los Estados Unidos para este tipo de estudiantes. El primer artículo es de Yuly Asención-Delaney, "Roles asignados a los aprendices de español como lengua heredada en las clases mixtas para principiantes," y en el mismo se identifican los papeles que los instructores asignan a los estudiantes de español como lengua herencia (SHL) ${ }^{2}$ en cursos para principiantes que no se han diseñado para esta población en particular. En este tipo de cursos mixtos de español participan estudiantes de herencia con estudiantes de español como segunda lengua, lo cual resulta en un desafío para el instructor, en cuanto a las necesidades específicas de cada grupo. Con este trabajo se explora la manera en la que lo roles asignados a los estudiantes de herencia sirven para apoyar las metas de SHL y para cumplir con las conexiones culturales necesarias en dichos casos.

1 Para una lista completa de los congresos que se han celebrado y las publicaciones que se han producido visite la página web http://spanishintheus.org/ Esta lista es una cortesía de las Dras. Kim Potowski y Jennifer Leeman.

2 De acuerdo a Valdés (2000), un hablante de herencia es "un estudiante que se crio en un hogar donde se hablaba una lengua que no fuera el inglés, el cual habla o simplemente entiende o comprende la lengua de herencia, y que es, hasta cierto punto, bilingüe en inglés y la lengua de herencia (p. 375). (Traducción nuestra). 
El segundo trabajo de esta sección de Mary Elizabeth Beaton "Interpretación de los acentos ortográficos como indicadores de hiato," también hace referencia al estudiante que tiene el español como parte de su herencia etnolingüística. En el mismo se examinan las percepciones silábicas entre hablantes de herencia $(\mathrm{HH})$, estudiantes de español como segunda lengua y hablantes monolingües del español en palabras con secuencias vocálicas $i o$. Con este estudio de carácter fonológico se ponen en evidencia las diferencias entre las intuiciones de los hablantes de herencia y las de los otros dos grupos, en la producción de diptongos y hiatos con la combinación io. Por medio de una prueba oral y otra auditiva, la autora analiza la manera en la que intuiciones de los hablantes de herencia se comparan con las de los otros dos grupos. Los resultados muestran que cuanto más temprano ha sido el contacto directo con el español, más posibilidad habrá de que el hablante produzca formas que se asemejen más a las de un hablante nativo.

Los trabajos del español en contacto con el inglés en los Estados Unidos se completan con el estudio de Patricia Gubitosi, Daniela Narváez y Christian Pumas titulado "El paisaje lingüístico de un barrio ecuatoriano en Queens, NY." Los estudios sobre el paisaje lingüístico incorporan fotos de rótulos y anuncios en el idioma de origen de la comunidad que se estudia, para analizar aspectos sobre mantenimiento lingüístico, transformación de espacios públicos y marca de identidad étnica y lingüística en dichos espacios. En este estudio se analiza la manera en la que una comunidad ecuatoriana que reside en la zona de Queens de la ciudad de Nueva York ha transformado el paisaje lingüístico de su entorno para hacerlo más parecido a lo que experimentan en su país de origen. Los autores de este estudio muestran la manera en la que grupos de latinos en los Estados Unidos construyen su identidad en espacios públicos. A la misma vez analizan la manera en la que la comunidad ecuatoriana se diferencia de otras comunidades inmigrantes en la creación de este espacio.

Los últimos dos trabajos de esta sección examinan fenómenos del español en contacto con otras lenguas. El primer estudio es de Silvia Kim, "El español y el coreano en contacto: nuevas percepciones sobre cambio de código," y continúa con una tradición larga sobre estudios de mezcla o cambio de código. En este artículo la autora examina la manera en la que las restricciones que se han propuesto en otros trabajos sobre el cambio de código entre el español y el inglés se pueden observar también en el contacto entre español y coreano. Asimismo, la autora examina otros patrones y restricciones que se evidencian en dicho contacto entre el español y el coreano, y que se convierten en un desafío para otros estudios sobre el tema. El análisis de Kim sirve para establecer diferencias tipológicas notables entre el español y el coreano, y contribuye a un tema que cuenta con una bibliografía muy amplia en el área de lenguas en contacto. 
Finalmente, concluimos los trabajos sobre el español en contacto con otras lenguas con el estudio de Farah Ali, "El multilingüismo y la aculturación en Cataluña: un análisis comparativo de mujeres inmigrantes musulmanas de primera y segunda generación." Los estudios sobre el español o castellano en contacto con otras lenguas minoritarias de España como euskera, catalán-valenciano y gallego han tomado un gran auge en los estudios lingüísticos de la Península. A eso habría que añadir el contacto del español/castellano con otras variedades de español de América Latina, y el contacto del español con el árabe y otras lenguas del norte de África. El artículo de Ali sirve de reflexión a los procesos de aculturación y de selección lingüística entre mujeres inmigrantes musulmanas en la Comunidad Autónoma de Cataluña. En el estudio no solamente se toman consideración los desafíos lingüísticos a los que se enfrentan dichas mujeres, sino también a las diferencias religiosas y de género. En el artículo se examina la manera en la que las mujeres del estudio favorecen el uso del español o del catalán, y los factores socioculturales que influyen en el uso o interés por una lengua o la otra. Además, se analizan diferencias generacionales y religiosas para la selección de una u otra lengua, y los factores socioculturales que influyen en dicha selección.

\section{Referencia}

Valdés, G. (2000) The teaching of heritage languages: An introduction for Slavic-teaching professionals. In 0. Kagan \& B. Rifkin (Eds.), The learning and teaching of Slavic languages and cultures (pp. 375-403). Bloomington, IN: Slavica. 